\title{
The Combination of Gravity and Welfare Approaches \\ for Evaluating Non-Tariff Measures
}

\author{
Anne-Célia Disdier $\quad$ Stéphan Marette
}

\begin{abstract}
This article explores the link between gravity and welfare frameworks for measuring the impact of non-tariff measures. First, an analytical approach suggests how to combine a gravity equation with a partial equilibrium model to determine the welfare impact of nontariff measures. Second, an empirical application focuses on the effects of a standard capping antibiotic residues in crustaceans in the United States, the European Union, Canada and Japan. While the econometric estimation of the gravity equation reports a negative impact on imports, welfare evaluations show that, in most cases, a stricter standard leads to an increase in both domestic and international welfare.
\end{abstract}

Keywords: Gravity Equation, Non-Tariff Measures, Seafood, Welfare

JEL classification: F1, Q1

\footnotetext{
- INRA, UMR Economie Publique INRA-AgroParisTech, 16 rue Claude Bernard, 75231 Paris Cedex 05, France. Emails: anne-celia.disdier@agroparistech.fr, marette@agroparistech.fr

The authors thank Sébastien Jean and participants at ETSG 2009 for helpful comments. Financial support received by the "AgFoodTrade - New Issues in Agricultural, Food and Bioenergy Trade" (Grant Agreement no.212036) research project, funded by the European Commission, is gratefully acknowledged. The views expressed in this paper are the sole responsibility of the authors and do not necessarily reflect those of the Commission.
} 


\section{Introduction}

Non-tariff measures (NTMs) are defined as interventions other than tariffs that affect trade of goods. With the reduction in tariffs under recent negotiations, NTMs are playing an increasing role in swaying international trade (United Nations Conference on Trade and Development 2005). ${ }^{1}$ The problem of NTMs is potentially pervasive with issues linked to sanitary crises in the agribusiness sector, market authorizations for genetically modified organisms, nanotechnologies or animal cloning, but also issues such as animal welfare, absence of recombinant bovine somatotropin, absence of antibiotic and pesticide residues, absence of child labour in some products from poor countries or carbon emissions linked to products.

The effects of NTMs are ambiguous and politically sensitive. On one side, regulations are often necessary to alleviate market failures, but on the other side, domestic regulations may be imposed simply to impede imports of foreign competitors (Beghin 2008). Theoretical analyses do not give any definitive conclusions on the overall effect linked to regulation, which requires economists to turn to empirical analyses. Evaluating impacts of such NTMs is not simple and requires tricky estimations (Dee and Ferrantino 2005).

In this article, we show how to take into account the coefficient measuring the forgone trade linked to NTMs in a gravity equation to determine the relative variations of both price and quantity in a partial equilibrium model used for welfare analysis, with the integration of experimental results to evaluate the damage for consumers.

The related application measures the impact of a stricter standard to cap residues of chloramphenicol in crustaceans. Chloramphenicol is an antibiotic often used in seafood farms in developing countries and is toxic to human health. The estimation of the coefficient

\footnotetext{
${ }^{1}$ Between 1995 and 2007, 261 specific trade concerns were examined by the World Trade Organization Sanitary and Phytosanitary Committee (World Trade Organization 2008).
} 
measuring the forgone trade via the gravity equation is integrated in a partial equilibrium model, calibrated to represent supplies of and demands for crustaceans in the United States, the European Union, Canada and Japan. This calibrated model allows us to measure the impact of the stricter standard on both foreign exporters' profits and domestic welfare defined as the sum of domestic producers' profits and consumers' surplus. While the econometric estimation of the gravity equation shows a negative impact of the standard on crustacean imports, welfare evaluations show that, in most cases, a stricter standard has led to an increase in both domestic and international welfare over the last decade because of a significant reduction in the chloramphenicol damage. In other words, NTMs can be traderestricting but welfare-enhancing.

Our article makes an important contribution to the literature on NTMs by bridging the gap between mercantilist and welfare approaches. Many recent empirical assessments of NTMs have been mercantilist focusing on forgone trade via gravity estimation (see for example Otsuki, Wilson, and Sewadeh 2001a and b; Wilson and Otsuki 2004; Disdier, Fontagné, and Mimouni 2008; Anders and Caswell 2009). However, such an approach is restrictive and hampers a more complete understanding of the actual effects of NTMs on all economic agents concerned (e.g. producers but also consumers, importers and governments). Other papers aim at developing a welfare approach of NTMs without gravity estimations (e.g. Dean 1995; Bureau, Marette, and Schiavina 1998; Paarlberg and Lee 1998; Beghin and Bureau 2001; Warr 2001; McCorriston and MacLaren 2005 and 2007; Wilson and Anton 2006; Yue, Beghin, and Jensen 2006; Pendell et al. 2007; Peterson and Orden 2008; Yue and Beghin 2009). The combination of both gravity and welfare methodologies in a partial equilibrium context has been completely overlooked by these studies and our article explicitly aims to remedy this absence. 
A second contribution of our article is to provide up-to-date estimates in terms of gravity equation estimation technology and to account for the impact of NTMs on both the probability that trade takes place (extensive margin) and the intensity of trade (intensive margin) by computing the full marginal effect.

The third contribution of our article is to estimate the welfare variations caused by a stricter standard for crustaceans in the United States, the European Union, Canada and Japan. This application is important since the welfare measures taking into account agents' surpluses justify the tightening of standards on imported crustaceans. Our approach differs from the previous seafood studies focusing only on the ex post evaluation of past measures on trade via econometric analysis (Hudson et al. 2003; Debaere 2005; Alberini et al. 2008; Anders and Caswell 2009). In this article, we evaluate past policies (over the period 2001-2006) but also a future policy with an ex ante analysis linked to a potential standard eliminating all chloramphenicol residues in seafood. Such a policy could be selected over the coming years (Ababouch, Gandini, and Ryder 2005; Buzby, Unnevehr, and Roberts 2008). The welfare study helps anticipate future price adjustments on markets and achieves quantified analyses directly usable by the public decision-maker.

The article is structured as follows. The next section presents both mercantilist and welfare approaches and their potential link from a theoretical point of view. The empirical application on crustacean products is provided in the third section. The last section concludes.

\section{A simple framework}

We briefly present both gravity and welfare approaches and their potential links by focusing on the impact of the standard.

\section{The gravity approach}


The trade effects of a NTM can be estimated by using a gravity equation. This equation provides a measure of the expected bilateral trade given the size of both partners and the bilateral transaction costs. By comparing expected and real trade, we obtain a measure of the trade effect of the NTM. The theoretical foundations of the gravity equation have been enhanced over the last few decades (see, among others, Anderson 1979; Bergstrand 1985; Anderson and van Wincoop 2003).

Our theoretical foundation for trade patterns is the standard new trade monopolistic competition-constant elasticity of substitution (CES) demand-Iceberg costs model introduced by Krugman (1980). Producers in each country operate under increasing returns to scale and produce differentiated varieties. These varieties are shipped with a cost to consumers in all countries. Following Redding and Venables (2004), the total value of exports from country $i$ to country $j$ can be written as follows:

$$
x_{i j}=n_{i} p_{i}^{1-\sigma}\left(T_{i j}\right)^{1-\sigma} E_{j} G_{j}^{\sigma-1}
$$

with $n_{i}$ and $p_{i}$ the number of varieties and prices in country $i, E_{j}$ and $G_{j}$ being the expenditure and price index of country $j . T_{i j}$ represents the iceberg transport costs and $\sigma$ the elasticity of substitution.

Different specifications of this equation have been estimated. The usual practice consists of proxying exporter and importer attributes with the gross domestic products (GDPs) and GDPs per capita of both countries. However, the relevance of this specification has been questioned for its distance to theory.

According to the theory, importer and exporter's attributes depend on their GDPs but also on their implicit price indexes. Anderson and van Wincoop (2003) call these price 
indexes the multilateral resistance terms, since they depend on the trade-cost term. ${ }^{2}$ The absence of control for multilateral resistance terms could bias the estimation. Multilateral resistance terms are unobserved but Anderson and van Wincoop (2003) suggest estimating a specification in which the country's attributes are a function of GDPs and bilateral linkages. This approach makes (1) non-linear in the parameters and they therefore estimate it via nonlinear least squares. An alternative solution is to rely on fixed effects by country. ${ }^{3}$

Transport costs are measured with the bilateral distance between both partners. We also control for adjacency: $\mathrm{cb}_{i j}$ is a dummy variable that equals one if the two countries share a border. Since cultural proximity can foster bilateral trade, we introduce two dummies, respectively equal to one if the two partners share a language $\left(\operatorname{clang}_{i j}\right)$ or have had a colonial relationship $\left(\right.$ colony $\left._{i j}\right)$. We also control for non-tariff $\left(\mathrm{NTM}_{i j t}\right)$ and tariff measures $\left(\mathrm{t}_{i j t}\right)$. Finally, we include a set of year dummies to capture time-specific effects. Therefore, after taking logs, equation (1) can be rewritten as follows:

$$
\ln x_{i j t}=\mathrm{fe}_{i}+\mathrm{fe}_{j}+\beta_{1} D_{i j}+\beta_{2} \mathrm{cb}_{i j}+\beta_{3} \operatorname{clang}_{i j}+\beta_{4} \operatorname{colony}_{i j}+\beta_{5} \mathrm{NTM}_{i j t}+\beta_{6} \mathrm{t}_{i j t}+\mathrm{fe}_{t}+\varepsilon_{i j t} .
$$

Equation (2) can be estimated using ordinary least squares (OLS). However, in that case, zero trade flows are dropped from the estimation, which could bias the results. One way to account for these flows is to use a sample selection model, such as the Heckman model. This model includes two equations: the first one (the selection equation) investigates the binary decision whether or not to trade and estimates it through a probit, while the second

\footnotetext{
${ }^{2}$ This approach assumes symmetric trade costs between source and destination countries. This strong assumption could provide biased empirical results (especially in the case of use of disaggregated data). This bias will not however greatly affect our estimations, which include few symmetric trade relationships (cf. infra our sample's composition).

${ }^{3}$ Other approaches have been suggested in the literature. Baier and Bergstrand (2009) suggest using a first-order log-linear Taylor expansion to approximate the multilateral resistance terms. It provides theoretically-motivated exogenous multilateral resistance terms, which are then introduced into a reduced-form gravity equation. Hallak (2006), Romalis (2007) and Head, Mayer, and Ries (2008) use the ratio of ratios to drop out indexes of the exporter and importer's attributes, including the multilateral resistance terms.
} 
(the outcome equation) focuses on the amount, if any, of trade. Both equations can be estimated simultaneously, using the maximum likelihood method, or successively. As suggested by Helpman, Melitz, and Rubinstein (2008), both the selection and outcome equations should include the same independent variables except one associated with the fixed trade costs of establishing a trade relationship. This excluded variable will only be included in the selection equation. Common language will be the excluded variable in our estimations. ${ }^{4}$

The Heckman approach allows investigation of the impact of a non-tariff measure on both probability of trade (extensive margin) and amount of trade (intensive margin). To do so, one should compute the full marginal effect, which is the sum of the effects of the NTM on the extensive margin (likelihood to trade) and on the intensive margin (conditional on trade taking place). If the NTM has no significant impact on the extensive and on the intensive margins of trade, no further welfare analysis of the NTM will be necessary. If one of the effects is statistically significant (at least on one margin), it will be used for the welfare analysis linked to NTM. If both effects are significant, their sum will be used.

By taking the derivative from (2) and by abstracting from indexes, the relative variation of exports in value linked to NTM can be defined as $d x / x=\beta_{5} d \mathrm{NTM}$ (everything else being constant). The value of exports in (2) is defined by $x=p . q$, where $p$ and $q$ are respectively the price and the quantity of exports. Thus, the relative variation of exports linked to the NTM can be rewritten as:

$$
\frac{d p}{p}+\frac{d q}{q}=\beta_{5} d \mathrm{NTM}
$$

\footnotetext{
${ }^{4}$ Helpman, Melitz, and Rubinstein (2008) also control for the unobserved firm-level heterogeneity bias that results from the variation in the fraction of firms that export from a source to a destination country. Their definition of the extensive margin (cf. infra) is therefore a bit different since it includes a change in the share of exporting firms.
} 
When the impact of the NTM is statistically significant, the gravity analysis can be integrated into a calibrated model via equation (3) that isolates the effect of the NTM variation from other effects. This measure provides precious information in a context where data linked to border inspections are extremely difficult to collect. As Ababouch, Gandini, and Ryder (2005, p. iii) mentioned in the introduction of an exhaustive study about border cases, their study "took over three years to finalize in its present form. A major difficulty was accessing essential data and in a format useful for their exploitation." Equation (3) can be applied uniformly across different importing countries for the welfare analysis. ${ }^{5}$ The following welfare analysis focuses on NTM impacts for a single country and its importers.

\section{The welfare approach}

The welfare measure takes into account agents' surpluses for evaluating a NTM. In a simplified framework, the market good being analyzed is assumed to be homogenous (i.e., same quality attributes) except for a specific characteristic that is potentially dangerous to consumers and linked to the foreign products. Therefore, only foreign producers are concerned by a standard reinforcement selected by the domestic regulator for reducing consumers' risk. This analytical simplification allows a sharper focus on the international implications of standards and particularly fits the empirical example of the next section. Demands are derived from quadratic preferences, and supply is derived from a quadratic cost function.

It is assumed that a representative consumer has the following utility function (Polinsky and Rogerson 1983):

$$
U\left(q_{f}, q_{d}, w\right)=a\left(q_{f}+q_{d}\right)-\frac{b\left(q_{f}^{2}+q_{d}^{2}+2 \theta q_{f} q_{d}\right)}{2}-I \gamma r q_{f}+w
$$

\footnotetext{
${ }^{5}$ A more accurate econometric estimation would be to add importer and exporter fixed effects interacted with the NTM variable in equation (2).
} 
where $q_{f}$ and $q_{d}$ are the respective consumptions of foreign and domestic products. The parameters $a, b>0$ allow the capture of the immediate satisfaction from consuming foreign and domestic products and $w$ is the numeraire good. The parameter $\theta$ measures the degree of substitutability between foreign and domestic products, with $\theta=0$ for independent products and $\theta=1$ for perfect substitutes.

The expected damage linked to the foreign products is captured by the term $I \gamma r q_{f}$. The parameter $r \geq 0$ is the per-unit damage and $\gamma$ is the probability of having a contaminated product with $0 \leq \gamma \leq 1$. With a probability $(1-\gamma)$, there is no damage. The parameter $I$ represents the consumer's knowledge regarding the specific characteristic brought by the foreign product. If the consumer is not aware of the specific characteristic, then $I=0$, and the cost of ignorance, $\gamma r q$, is negatively taken into account in the welfare. In other words, the value $-\gamma r q$ disappears from the utility (4) when $I=0$, but is taken into account in the welfare by a regulator accounting for all the characteristics linked to a product. Conversely, $I=1$ means that the consumer is aware of the specific characteristic and negatively internalizes the damage in her/his consumption. ${ }^{6}$ The maximization of utility defined by (4) with respect to $q_{f}$ and $q_{d}$, subject to the budget constraint with prices $p_{f}$ for foreign goods and $p_{d}$ for domestic goods gives the respective demands $q_{f}^{D}=\left[a(1-\theta)-p_{f}+\theta p_{d}-I \gamma r\right] /\left[b\left(1-\theta^{2}\right)\right]$ and $q_{d}^{D}=\left[a(1-\theta)-p_{d}+\theta p_{f}+\theta I \gamma r\right] /\left[b\left(1-\theta^{2}\right)\right]$.

For the rest of the article, we focus on the situation where the damage is not internalized (with $I=0$ ), which is realistic for the situation presented in the following section (the internalized case with $I=1$ would directly impact the demand). To simplify the presentation

\footnotetext{
${ }^{6}$ It is also possible to consider the case with $I$ taking a value between 0 and 1 , namely for situations where consumers are partially aware of the characteristic.
} 
and because of the lack of data in the forthcoming example, we consider domestic and foreign goods as perfect substitutes with $\theta=1$. The maximization of (4) with $\theta=1$, $p_{f}=p_{d}=p$ and $Q=q_{f}+q_{d}$ leads to an overall demand $Q^{D}=(a-p) / b$ and an inverse demand $p^{D}=a-b Q$ with $I=0$.

On the supply side, a perfectly competitive industry comprising domestic and foreign firms with price-taking firms is assumed. A stricter standard has two major impacts on foreign firms. ( $i$ ) First, it reduces the proportion of foreign products entering a market because of tougher inspections linked to stricter thresholds, particularly for firms with difficulties complying with the stricter standard. Empirically, this effect was observed in Europe, where the 2001 chloramphenicol standard drastically increased the number of border cases. Indeed, the chloramphenicol cases represented $0 \%$ of European border cases for seafood in 2000 versus 36\% in 2002 (Ababouch, Gandini, and Ryder 2005, table 19 p. 32). (ii) Second, compliance with the stricter standard brings about an increase in marginal costs and sunk costs (linked to investments that are sunk once undertaken). An increase in marginal costs leads farmers to reduce the quantities supplied for each given price. Sunk investments do not figure in farmers' optimal supplied quantities and have more indirect effects on market prices through the entry and exit of farmers. Empirically, shrimp producers adjusted to the stricter standard by selecting new shrimp varieties and starting to adopt Hazard Analysis Critical Control Point (HACCP) programs (Anders and Caswell 2009). For the rest of the study and for the sake of simplicity, we only focus on the first effect $(i)$, namely the reduction of the proportion of foreign products entering the market. However, note that both explanations ( $i$ ) and (ii) lead to similar impacts since they contribute to reducing the quantities supplied by farmers and tend to increase the resulting equilibrium prices. 
We focus on a representative foreign producer subsuming all producers. ${ }^{7}$ This representative foreign producer maximizes its profit:

$$
\pi_{f}=\frac{p}{1+t} \lambda q_{f}-g_{f} q_{f}-\frac{c_{f} q_{f}^{2}}{2}-K_{f}
$$

where $c_{f}, g_{f}$ are the variable cost parameters and $K_{f}$ is the sunk cost linked amongst others to the firm's market entry and compliance with regulations (for the rest of the presentation, $K_{f}$ is zero only for the sake of simplicity). The parameter $\lambda$ is the proportion of foreign products entering the domestic market when an output $q_{f}$ is offered before the border inspection. This proportion $0 \leq \lambda \leq 1$ depends on the standard and the inspection policy. Under the assumption of rational expectations, the expected proportion taken into account by the producer corresponds to the effective proportion linked to the policy. The more stringent the standard and the inspection policy, the lower the proportion of products entering the market. The parameter $t$ is the ad-valorem tariff on imports, implying a price $p /(1+t)$ received by the foreign producers when domestic consumers pay $p$. To simplify the presentation, it is assumed that $t=0$.

The representative producer maximizes its profits with respect to $q_{f}$ leading to a foreign supply before the inspection equal to $q_{f}^{S}=\left(\lambda p-g_{f}\right) / c_{f}$. After the inspection, the foreign supply of products entering the domestic market is $Q_{f}^{S}=\lambda q_{f}^{S}$. The foreign inverse supply of products entering the domestic market is $p_{f}^{S}=\left(c_{f} Q_{f}+\lambda g_{f}\right) / \lambda^{2}$.

Using similar notations to equation (5), the representative domestic producer maximizes the profit given by $\pi_{d}=p q_{d}-g_{d} q_{d}-1 / 2 c_{d} q_{d}^{2}$. The difference with (5) comes from the absence

\footnotetext{
${ }^{7}$ The proportion of goods entering the domestic market also represents the combination of producer's probabilities of being fully excluded from the domestic market when a small producer is detected with contaminated products.
} 
of the parameter $\lambda$ linked to the standard since it is assumed that domestic producers already complied with it. This was the case with the new 2001 policy that mainly impacted Asian exporters, since the chloramphenicol was already banned in many OECD countries as, for instance, in the European Union since 1994. The supply is $q_{d}^{S}=\left(p-g_{d}\right) / c_{d}$ and the inverse supply is $p_{d}^{S}=c_{d} q_{d}+g_{d}$. The total supply defined by the sum of foreign and domestic supply is $Q^{S}=Q_{f}^{S}+q_{d}^{S}=\left[\left(\lambda^{2} c_{d}+c_{f}\right) p-c_{d} \lambda g_{f}-c_{f} g_{d}\right] / c_{d} c_{f}$. The total inverse supply is $p^{S}=\bar{c} q+\bar{g}$ with $\bar{c}=c_{d} c_{f} /\left(\lambda^{2} c_{d}+c_{f}\right)$ and $\bar{g}=\left(c_{d} \lambda g_{f}+c_{f} g_{d}\right) /\left(c_{d} \lambda^{2}+c_{f}\right)$.

Figure 1 shows domestic demand $(D)$, foreign supply $\left(S_{F}\right)$ and total supply $(S)$ (the domestic supply is omitted for the clarity of figure 1). The price, $p$, is located on the vertical axis and the quantity, $q$, is shown along the horizontal axis.

\section{Insert figure 1 here}

For an initial situation $\mathrm{A}$, linked to a proportion $\lambda$, the equilibrium price $p^{A}=(a \bar{c}+b \bar{g}) /(\bar{c}+b)$ clears the market by equalizing demand and supply with an overall equilibrium quantity $Q_{A}=(a-\bar{g}) /(\bar{c}+b)$ (such that $p^{S}=p^{D}$ with $\left.I=0\right)$. In figure $1, Q_{A}^{f}$ is foreign output and $Q_{A}-Q_{A}^{f}$ is domestic output. The profits correspond to area $O w v p^{A}$ for foreign producers (since sunk costs are zero) and area $w z A v$ for domestic producers. The usual surplus of domestic consumers corresponds to area $p^{A} A a$. The damage linked to foreign products does not impact the demand since $I=0$. However, the cost of ignorance should be accounted for in the welfare calculations and is equal to $\gamma r Q_{A}^{f}$ represented by the area $0(-\gamma r) t Q_{A}^{f}$. Domestic welfare is the sum of domestic producers' profits and consumer surplus minus the cost of ignorance and is given by area $\left(p^{A} v w z A a-0(-\gamma r) t Q_{A}^{f}\right)$. International welfare is the sum of domestic welfare and foreign producers' profits and is 
given by area $\left(0 z A a-0(-\gamma r) t Q_{A}^{f}\right)$. Full analytical expressions for equilibrium values as well as for all the components of welfare are easy to compute and can be provided upon request.

With this initial situation preceding a reinforcement of the regulation, parameters of the model are initially calibrated in such a way as to replicate prices and quantities over a period. With the observed quantity $\hat{Q}$ sold over a period, the average price $\hat{p}$ observed over the period, and the direct price elasticity $\hat{\varepsilon}\left(=p \cdot d Q^{D} /\left(Q^{D} \cdot d p\right)\right)$ obtained from econometric estimates, the calibration leads to estimated values for the demand equal to $1 / \tilde{b}=-\hat{\varepsilon} \hat{Q} / \hat{p}$, $\tilde{a}=\tilde{b} \hat{Q}+\hat{p}$ (the same method can be used for the supply side with a given proportion $\lambda$ ). The value of $r$ can be provided by experimental studies or by consumers' surveys.

When a standard is reinforced, the market allocation is modified as represented in figure 1 with bold curves and point B. First, a stringent policy increases border cases and consignments of tainted food (Ababouch, Gandini, and Ryder 2005), which reduces the proportion of entering the domestic market from $\lambda$ to $\bar{\lambda}$ for foreign producers. The supply shifts upward from $(S)$ to $\left(S^{\prime}\right)$ leading to an equilibrium price $p^{B}$ and an overall equilibrium quantity $Q_{B}$. The stricter policy increases the price with $p^{B}>p^{A}$ and decreases the quantity with $Q_{B}<Q_{A}$. It also reduces the probability of having contaminated products from $\gamma$ to $\bar{\gamma}$ and the overall damage for unaware consumers. At point B, domestic welfare is the sum of domestic producers' profits and consumer surplus with the cost of ignorance linked to foreign production $Q_{B}^{f}$ and is given by area $\left(p^{B} k h n B a-0(-\bar{\gamma} r) u Q_{B}^{f}\right)$. The profits correspond to area $0 h p^{B}$ for foreign producers. International welfare is the sum of domestic welfare and foreign producers' profits and is given by area $\left(\mathrm{OnBa}-0(-\bar{\gamma} r) u Q_{B}^{f}\right)$. 
The effect of a stricter standard, i.e. the comparison between the initial domestic welfare $\left(p^{A} v w z A a-0(-\gamma r) t Q_{A}^{f}\right)$ and the new domestic welfare $\left(p^{B} k h n B a-0(-\bar{\gamma} r) u Q_{B}^{f}\right)$, is ambiguous (a similar demonstration could be made between international welfare measures $\left(0 z A a-0(-\gamma r) t Q_{A}^{f}\right)$ and $\left.\left(O n B a-0(-\bar{\gamma} r) u Q_{B}^{f}\right)\right)$. If area $\left(p^{B} k m p^{A}+n z A B\right)$ is lower than area $\left(w h m v+(-\bar{\gamma} r) u Q_{B}^{f} Q_{A}^{f} t(-\gamma r)\right)$, the increase in price is low enough for the regulation reinforcement to be beneficial to the domestic country. Alternatively, area $\left(p^{B} k m p^{A}+n z A B\right)$ could be larger than area $\left(w h m v+(-\bar{\gamma} r) u Q_{B}^{f} Q_{A}^{f} t(-\gamma r)\right)$, when the regulation reinforcement involves a relatively large contraction in the supply. In this case, additional regulation would result in domestic welfare losses since the price effect offsets the damage reduction effect. With a stricter standard, foreign producers will be injured by such a decision, if area $p^{B} k m p^{A}$ is lower than area whmv.

The change in the probability of having contaminated products, from $\gamma$ to $\bar{\gamma}$, can be exogenously given or measured by studying the border inspection policy when the information is available. When the coefficient $\beta_{5}$ is statistically significant, equation (3) coming from the gravity equation can be used with this welfare analysis to measure the price/quantity effects linked to the stricter standard influencing the imports of foreign products with a change of the parameter $\lambda$ to $\bar{\lambda}$. With the notation of figure 1 , and by focusing on discrete variations with $\triangle \mathrm{NTM}$ measuring the stricter-standard impact, equation (3) can be rewritten as:

$$
\frac{\left(p^{B}-p^{A}\right)}{p^{A}}+\frac{Q_{B}^{f}-Q_{A}^{f}}{Q_{A}^{f}}=\beta_{5} \Delta \mathrm{NTM}
$$


For a given value $\lambda$ linked to the equilibrium $\mathrm{A}$, the value of $\bar{\lambda}$ is determined by solving (6). ${ }^{8}$ This value $\bar{\lambda}$ depends on the gravity coefficient $\beta_{5}$ of equation (2) and provides a measure of trade restrictions and welfare impacts.

This link between the gravity and welfare approaches was overlooked by the previous literature and allows us to turn to the empirical estimation linked to the crustacean market.

\section{The Crustacean Example}

Production and trade of crustacean products ${ }^{9}$ have seen a significant rise over the last decade, since between 1996 and 2006, the quantity produced increased by 54.1\%. In 2006, Asian countries accounted for $77.4 \%$ of world production, and OECD imports represented $91.1 \%$ of world crustacean imports in value and $85.5 \%$ in quantity (United Nations Food and Agriculture Organization - UN FAO - 2009). However, this boom comes at some health costs. $^{10}$ To prevent and treat bacterial infections (e.g. salmonella) and other pathogens, crustacean producers use a range of pesticides, harmful drugs and antibiotics (such as chloramphenicol), which are highly toxic to human health.

To protect their consumers, importing countries adopted sanitary measures and banned contaminated consignments. In 2001, after detection of high levels of chloramphenicol residues, the European Union banned any consignment of shrimps from China, India, Pakistan and Southeast Asian countries tested positive (Ababouch, Gandini, and Ryder 2005). In January 2002, the European Union imposed a 30-month ban on shrimp imports from China because of illegal antibiotic use. Between 2003 and 2005, Canada imposed 100\% testing of

\footnotetext{
${ }^{8}$ Alternatively, the standard could equally influence foreign and domestic producers leading to an alternative equation $\left(p^{B}-p^{A}\right) / p^{A}+\left(Q_{B}-Q_{A}\right) / Q_{A}=\beta_{5} \Delta \mathrm{NTM}$, replacing equation (6).

${ }^{9}$ Crustacean products include a large proportion of shrimps relatively to other crustaceans.

${ }^{10}$ Concerns are also related to the environment (destruction of mangroves) and social costs (corruption of authorities, employment of children and of illegal immigrants). However, we will not address these concerns in the article.
} 
seafood imports from Vietnam after repeated detections of chloramphenicol. In July 2004, the European Union started to import Chinese shrimps again only after the Chinese government guaranteed that it would test $100 \%$ of shrimp exports. In 2006 , the United States rejected shrimp imports from China because of repeated antibiotics contamination. In December 2006, Japan imposed 100\% testing on Vietnamese shrimps after repeated chloramphenicol findings. In 2007, the European Union imposed a ban on Thai shrimps contaminated with chloramphenicol and decertified all seafood producers from Pakistan. ${ }^{11}$ The following gravity estimation linked to equation (2) aims to integrate some of these regulatory measures taken by importing countries to combat the chloramphenicol problem.

\section{The gravity estimation}

The data used to estimate (2) with the crustacean case are now presented. Our trade data come from the United Nations Commodity Trade Statistics Database (COMTRADE). We focus on bilateral imports of crustaceans. We select the main importing countries of crustaceans, namely Canada, Japan, the United States and the European countries (European Union-15 taken separately) and analyse their imports from all exporting countries over the 2001-2006 period. Bilateral distances are calculated as the sum of the distances between the biggest cities (in terms of population) of the two countries. The dummy variable $\mathrm{cb}_{i j}$ is set to 1 for pairs of countries that share a border. Similarly, clang $_{i j}$ and colony $i j$ are dummies equal to 1 if the two partners share a language or have had a colonial relationship. Data for these variables are extracted from the CEPII (Centre d'Etudes Prospectives et d'Informations Internationales) database on distance and geographical variables. ${ }^{12}$

\footnotetext{
${ }^{11}$ See Ababouch, Gandini, and Ryder (2005), Southern Shrimp Alliance (2007) and http://www.seafoodnews.com/ (available May 2009).

${ }^{12}$ http://www.cepii.fr/anglaisgraph/bdd/distances.htm (available May 2009).
} 
The NTM variable is defined using the Maximum Residue Limit (MRL) in part per billion (ppb) for chloramphenicol applied by each importing country since 2001. This approach is similar to the one presented in Otsuki, Wilson, and Sewadeh (2001a and b). MRLs vary between countries ${ }^{13}$ and years. Following the repeated detections of chloramphenicol in crustacean imports and improvement in detection methods, countries lowered the detection limits.

We do not specifically control for bilateral tariffs, and this for two reasons. First, bilateral tariffs do not vary significantly over time. Second, while yearly data on bilateral tariffs are available in the Trade Analysis Information System (TRAINS) database, there are many missing values and these data do not include all specific duties, tariff quotas and antidumping duties applied by importing countries. In our estimations, the influence of bilateral applied protection is partly captured by country and year fixed effects.

Table 1 presents the results. Importer and exporter fixed effects, as well as year dummies are included in all our regressions. Furthermore, the correlation of errors across years for the same country-pair is taken into account by appropriate clustering and heteroskedasticity is corrected with White's (1980) method. Model (1) provides the simple OLS estimation on the sample of observations for which a positive trade relationship is observed. Model (2) applies the Heckman selection procedure and accounts for zero trade flows. It uses the maximum likelihood estimator and common language is the excluded variable in the trade equation. This choice is based on Helpman, Melitz, and Rubinstein (2008, footnote 37). ${ }^{14}$ Besides, model (1) shows that common language does not influence the

\footnotetext{
${ }^{13}$ In the European Union, the MRL is defined at the European level and applied by all Member States.

${ }^{14}$ Helpman, Melitz, and Rubinstein (2008) also use regulation costs and common religion as excluded variables. However, such data are not available for all countries included in our sample. To avoid a substantial drop in sample size, we do not use these variables as excluded ones in our estimations.
} 
amount of trade in our sample. For model (2), we report both structural coefficient estimates and marginal effects at sample means.

Insert table 1 here

Our results in column (1) are in line with the gravity literature. Distance has a negative and significant impact on the amount of trade flows, while contiguity and past colonial links foster bilateral trade. The common language variable is not significant. One explanation could be that crustacean products are homogeneous goods. Trade of homogeneous goods seems to be less influenced by cultural linkages than trade of differentiated products (Rauch 1999). As expected, the standard on chloramphenicol has a positive impact on trade (significant with $p=0.07$ ). In other words, the lower the MRL allowed by the importing country, the lower the imports. However, these results are potentially biased, since they are based only on positive trade flows.

Model (2) includes zero flows. The selection equation shows a negative and significant impact of distance and a positive and significant effect of colonial links and common language on the probability of trade. Interestingly, our results suggest that the decision whether to trade or not is not affected by the MRL. This result differs from Jayasinghe, Beghin, and Moschini (2009). These authors find that the sanitary and phytosanitary count variable used in their estimations has a significant impact on both the probability and the amount of trade. The estimated correlation coefficient $(\hat{\rho})$ and the estimated selection coefficient $(\hat{\lambda})$ are statistically significant, confirming that the absence of control for zero flows generates biased results.

The amount of trade is much more impacted by distance than the probability of trade. Results for the trade equation also show that this amount is positively and significantly 
influenced by contiguity and colonial links. MRL also has a positive and significant effect on the amount of trade $(p=0.07)$. This latter result suggests that the reinforcement of the standard between 2001 and 2006 (corresponding to a MRL decrease) had a negative impact on the amount of crustacean imports. In the next subsection, we will use the marginal effect of the standard on trade to estimate the welfare effect of past and future decisions regarding the acceptable levels of chloramphenicol residues. Since the MRL variable has no significant impact on the probability of trade (selection equation), we will just consider the marginal effect of the MRL factor on the amount of trade $(0.13$, see last column of table 1$)$ for the welfare analysis.

\section{The welfare estimation}

Standards that cap chloramphenicol residues have an impact on welfare, since the resulting foreign-supply shift influences both equilibrium price and cost of ignorance (see figure 1). By integrating the estimated-marginal effect of the MRL on the amount of trade in the calibrated model, it is possible to assess the costs and benefits of a stricter standard. The framework of the previous section based on equations (4) and (5) is directly used for this welfare estimation. In particular, domestic suppliers are not impacted by the MRL regulation. Indeed, the new 2001 policy mainly impacted Asian exporters since chloramphenicol was already banned in many OECD countries (for example since 1994 in the European Union).

Parameters of the model are initially calibrated so as to replicate prices and quantities for the year 2001 and 2006 in the United States, Canada, Japan and the European Union. These importing countries are considered without any interference with each other for the standard compliance by foreign producers. With the baseline scenario (namely before the reinforcement of the standard), it is assumed that the initial probability of contamination is $\gamma=1$ (see equation (4)) and the initial proportion of foreign products entering the domestic 
market is $\lambda=1$ (see equation (5)). Table 2 details the parameters used for calibrating the baseline scenario represented by the situation $\mathrm{A}$ in figure 1 .

\section{Insert table 2 here}

The value of the per-unit damage, $r$, defined in equation (4), is determined by using results from Lusk, Norwood, and Pruitt (2006) who elicited consumers' willingness-to-pay (WTP) in order to avoid antibiotics. From a consumer survey in the grocery store environment in the United States and a multinomial logit estimation, we have the mean WTP for pork without antibiotic. The multinomial logit estimation allows us to isolate the premium for the absence of antibiotic. The percent price premium for antibiotic-friendly product over conventional product is equal to $76.704 \%$ (see table 2 p. 1025 in Lusk, Norwood, and Pruitt 2006). For each country, we apply the domestic price $p^{A}$ used for the initial calibration, which means that the per-unit damage is equal to $r=0.767 \times p^{A}$ for each country and leads to the cost of ignorance. From model (2) of table 1, the marginal effect of the MRL factor is equal to 0.13 and included in equation (6) as $\beta_{5}$. For a given variation of the MRL with $\Delta \mathrm{NTM}=\Delta \mathrm{MRL}$, equation (6) is solved to determine $\bar{\lambda}$ linked to the shift of the foreign supply. $^{15}$

Table 3 presents ex post estimations of welfare variation for the year 2001 in the United States, the European Union, Canada and Japan. This table focuses on the impact of past MRL reductions specific to each country and observed between 2001 and 2006 (for each country $\triangle \mathrm{MRL}$ comes from the difference between the last lines of table 2 and is indicated in the first column of table 3). To measure different possibilities regarding the efficiency of the policy

\footnotetext{
${ }^{15}$ The proportion $\bar{\lambda}$ coming from (6) and welfare shifts of tables 3 and 4 were computed with the Mathematica software and are available upon request.
} 
characterized by $\triangle \mathrm{MRL}$, we distinguish between case 1 with a probability of contamination $\bar{\gamma}=3 / 4$, and case 2 with a probability $\bar{\gamma}=1 / 2$.

\section{Insert table 3 here}

For each country, table 3 presents the variation in domestic consumers' surplus (including the cost of ignorance linked to the damage), the variation in domestic producers' profits, the variation in foreign producers' profits and the relative variation in international welfare, which includes both domestic welfare and foreign producers' profits. The difference between cases 1 and 2 only concerns the cost of ignorance that does not impact the price, which explains the similar variations in profits in both columns for domestic and foreign producers.

For the United States, Canada and the European Union, table 3 shows that the domestic welfare variation is always positive (domestic welfare includes producers' and consumers' surpluses). Domestic consumers benefit from the reduction in the cost of ignorance that outweighs the negative effects coming from the price increase linked to the import restrictions. Domestic producers benefit from the increase in domestic price. The profit variation for foreign producers is always negative despite the price increase, since their sold quantities are strongly reduced. The foreign producers' losses outweigh the domestic welfare increase only for the United States leading to a decrease in international welfare. For the United States, the variations are similar for both cases (and columns), since the large MRL variations lead to the full elimination of foreign imports (with $\bar{\lambda}=0$ ), which corresponds to a drastic standard. ${ }^{16}$ Otherwise, for Canada and the European Union, the foreign producers' losses are outweighed by the domestic welfare increase, leading to an increase in international welfare. The more efficient the regulation (i.e., $\gamma$ lower), the higher both

${ }^{16}$ This case is such that $\left(p^{B}-p^{A}\right) / p^{A}+\left(Q_{B}-Q_{A}\right) / Q_{A}<\beta_{5} \Delta \mathrm{NTM}$ for $\bar{\lambda}=0$. 
domestic and international gains linked to the regulation leading to the MRL reduction observed between 2001 and 2006. Japan did not change its import standard between 2001 and 2006 , leading to the absence of welfare variation.

Two remarks can be added to table 3. First, we abstracted from the cost of regulation and inspection linked to the standard. By considering international (or domestic) welfare in table 3, this cost could be subtracted from it for having the net-social benefit of regulation and inspection. ${ }^{17}$ Second, under cases 1 and 2, the European Union shows the largest relative variation in international welfare, which ex post explains its appetite for more regulation.

Table 4 presents some ex ante estimations of the welfare effects for the year 2006 with a MRL equal to zero. ${ }^{18}$ From the last line of table 2, the variation of MRL to reach zero tolerance is $\triangle \mathrm{MRL}=-0.3$ for countries, except for Japan for which the variation is $\triangle \mathrm{MRL}=-$ 50. Note that as not all the products are inspected, the (in)efficiency of the policy is still acute justifying two new cases regarding the value of $\gamma$. With the new baseline scenario (before the reinforcement of the standard), it is assumed that $\lambda=1$ and $\gamma=3 / 4$, since some previous measures were already existing. To measure different possibilities regarding the efficiency of a stricter standard in table 4, we will distinguish between case 3 with the probability of contamination $\bar{\gamma}=1 / 2$ and case 4 , where $\bar{\gamma}=1 / 4$.

\section{Insert table 4 here}

Table 4 shows large domestic welfare gains for the United States, Canada and the European Union with a similar interpretation to the one provided in table 3. As the MRL is already low (namely a relatively high standard), reinforcing the standard towards zero

\footnotetext{
${ }^{17}$ The inspections and regulatory costs can be borne by consumers, domestic producers, taxpayers and/or foreign producers depending on the selected fee (per-unit fee or fixed fee) that finances the inspection policy (see Crespi and Marette 2001).

${ }^{18}$ This situation with a MRL=0 does not correspond to a strict zero tolerance policy because of flaws in the test procedures and the impossibility of testing all the products.
} 
tolerance brings a large gain for consumers via the reduction of the cost of ignorance, while the price effect linked to the import restriction following the standard enforcement is relatively low. For Japan, the large adjustment for some foreign producers not complying with pre-existing stringent standards in other countries makes the new standard costly and explains the decline of consumers' surplus, foreign producers' profits and international welfare. For Japan, the variations are similar for both cases (and columns), since the large MRL variations lead to the full elimination of foreign imports (with $\bar{\lambda}=0$ ), which corresponds to a drastic standard.

\section{Conclusion}

Using a very stylized framework, we studied how gravity models can be used for welfare analysis. With our application based on crustacean products, we measured the impact of standards capping chloramphenicol residues. While the econometric estimation of the gravity equation shows a negative impact on imports, welfare evaluations show that, in most cases, a stricter standard leads to an increase in both domestic and international welfare. This is an important result since this analysis of international welfare justifies tightening the food safety standards on imported crustaceans. This application illustrates the danger of treating NTMs as equivalent to tariffs restricting trade. NTM reduction without a clear welfare framework may be groundless and erroneous. Trade reductions and trade costs can be welfare improving in a second best setting, since it alleviates market failures that should be taken into account.

In order to focus on the main economic mechanisms and to keep the mathematical aspects as simple as possible, the analytical framework was admittedly simple. In order to fit different problems coming from various contexts, some extensions could be integrated into the model presented here. For instance, the crustacean species could be refined in the estimations. Taking into account the selection of alternative species less sensitive to residues 
by producers (such as the Penaeus Vannamei) may lead to a dynamic welfare approach. Data allowing demand and supply elasticities specific to each country could be considered. Eventually, the case where the damage is internalized in the consumers' demand can also be developed.

Our approach suggests that it is especially imperative for governments to examine both gravity and welfare approaches when NTMs are analyzed. First, the gravity estimation helps know whether or not a specific NTM really impacts trade by eliciting a statistically (non)significant effect. Second, the integration of a statistically significant effect in a calibrated model provides a rigorous welfare measure of the NTM.

These results for estimating welfare variations particularly help assess the impacts of ex ante regulatory measures, that is to say, before the effective implementation of food, environmental or health policies. The gravity and experimentation/survey results are a basis for anticipating market reactions and they help anticipate the regulatory adjustments on markets and achieve quantified analyses directly usable by the public decision-maker or by the World Trade Organization when there is a conflict over NTMs. This methodology combining gravity and welfare approaches may be systematically mobilized for cost-benefit analyses enlightening the decision-makers on the consequences of various public choices. 


\section{References}

Ababouch, L., G. Gandini, and J. Ryder. 2005. "Detentions and Rejections in International Fish Trade." Fisheries technical paper 473, Food and Agriculture Organization, Rome.

Alberini, A., E. Lichtenberg, D. Mancini, and G. Galinato. 2008. "Was It Something I Ate? Implementation of the FDA Seafood HACCP Program." American Journal of Agricultural Economics 90(1):28-41.

Anders, S.M., and J. Caswell. 2009. "Standards as Barriers Versus Standards as Catalysts: Assessing the Impact of HACCP Implementation on U.S. Seafood Imports." American Journal of Agricultural Economics 91(2):310-321.

Anderson, J.E. 1979. "The Theoretical Foundation for the Gravity Equation." American Economic Review 69(1):106-116.

Anderson, J.E., and E. van Wincoop. 2003. "Gravity with Gravitas: A Solution to the Border Puzzle." American Economic Review 93(1):170-192.

Asche, F., and T. Bjørndal. 2001. "Demand Elasticities for Fish and Seafood: A Review." Unpublished, Centre for Fisheries Economics, Norwegian School of Economics and Business Administration.

Baier, S.L., and J.H. Bergstrand. 2009. "Bonus Vetus OLS: A Simple Method for Approximating International Trade-Cost Effects Using the Gravity Equation." Journal of International Economics 77(1):77-85.

Beghin, J. 2008. "Nontariff Barriers." In S. Darlauf and L. Blume, eds. The New Palgrave Dictionary of Economics. $2^{\text {nd }}$ edition. New York NY: Palgrave Macmillan LTD, pp. 126129.

Beghin, J., and J-C. Bureau. 2001. "Quantitative Policy Analysis of Sanitary, Phytosanitary and Technical Barriers to Trade." Economie Internationale 87:107-130.

Bergstrand, J. 1985. "The Gravity Equation in International Trade: Some Microeconomic Foundations and Empirical Evidence." Review of Economics and Statistics 67(3):474-481.

Bureau, J-C., S. Marette, and A. Schiavina. 1998. "Non-Tariff Trade Barriers and Consumers' Information: The Case of EU-US Trade Dispute on Beef." European Review of Agricultural Economics 25(4):437-462.

Buzby, J.C., L.J. Unnevehr, and D. Roberts. 2008. Food Safety and Imports: An Analysis of FDA Food-Related Import Refusal Reports. Washington DC: U.S. Department of Agriculture, ERS Econ. Information Bulletin 39. September.

Crespi, J., and S. Marette. 2001. "How Should Food Safety Certification Be Financed?" American Journal of Agricultural Economics 83(4): 852-861.

Dean, J.M. 1995. "Export Bans, Environment, and Developing Country Welfare." Review of International Economics 3(3):319-329.

Debaere, P. 2005. "Small Fish-Big Issues: The Effect of Trade Policy on the Global Shrimp Market.” Discussion paper 5254, Centre for Economic Policy Research, London.

Dee, P., and M. Ferrantino. 2005. Quantitative Methods for Assessing the Effects of NonTariff Measures and Trade Facilitation. Singapore: APEC Secretariat and World Scientific Publishing Co. 
Dey, M.M., U-P. Rodriguez, R.M. Briones, C.O. Li, M.S. Haque, L. Li, P. Kumar, S. Koeshendrajana, T.S. Yew, A. Senaratne, A. Nissapa, N.T. Khiem, and M. Ahmed. 2004. "Disaggregated Projections on Supply, Demand, and Trade for Developing Asia: Preliminary Results from the Asiafish Model." Paper presented at IIFET Meeting, Tokyo, 21-30 July.

Disdier, A-C., L. Fontagné, and M. Mimouni. 2008. "The Impact of Regulations on Agricultural Trade: Evidence from SPS and TBT Agreements." American Journal of Agricultural Economics 90(2):336-350.

Hallak, J-C. 2006. "Product Quality and the Direction of Trade." Journal of International Economics 68(1):238-265.

Head, K., T. Mayer, and J. Ries. 2008. "The Erosion of Colonial Trade Linkages After Independence.” Discussion paper 6951, Centre for Economic Policy Research, London.

Helpman, E., M. Melitz, and Y. Rubinstein. 2008. "Estimating Trade Flows: Trading Partners and Trading Volumes." Quarterly Journal of Economics 123(2):441-487.

Hudson, D., D. Hite, A. Jaffar, and F. Kari. 2003. "Environmental Regulation through Trade: The Case of Shrimp.” Journal of Environmental Management 68(3):231-238.

Jayasinghe, S., J. Beghin, and G. Moschini. 2009. "Determinants of World Demand for U.S. Corn Seeds: The Role of Trade Costs." Working paper 484, Center for Agricultural and Rural Development, Iowa State University, Ames.

Krugman, P.R. 1980. "Scale Economies, Products Differentiation and the Pattern of Trade." American Economic Review 70(5):950-959.

Lusk, J.L., B. Norwood, and R. Pruitt. 2006. "Consumer Demand for a Ban on Subtherapeutic Antibiotic Use in Pork Production." American Journal of Agricultural Economics 88(4):1015-1033.

McCorriston, S., and D. MacLaren. 2005. "The Trade Distorting Effect of State Trading Enterprises in Importing Countries.” European Economic Review 49(7):1693-1715.

. 2007. "Deregulation as (Welfare Reducing) Trade Reform: The Case of the Australian Wheat Board." American Journal of Agricultural Economics 89(3):637-650.

Otsuki, T., J.S. Wilson, and M. Sewadeh. 2001a. "Saving Two in a Billion: Quantifying the Trade Effect of European Food Safety Standards on African Exports." Food Policy 26(5):495-514.

. 2001b. "What Price Precaution? European Harmonisation of Aflatoxin Regulations and African Groundnut Exports." European Review of Agricultural Economics 28(3):263-283.

Paarlberg, P.L., and J.G. Lee. 1998. "Import Restrictions in the Presence of a Health Risk: An Illustration Using FMD." American Journal of Agricultural Economics 80(1):175-183.

Pendell, D.L., J. Leatherman, T.C. Schroeder, and G.S. Alward. 2007. "The Economic Impacts of a Foot-And-Mouth Disease Outbreak: A Regional Analysis." Journal of Agricultural and Applied Economics 39:19-33.

Peterson, E.B., and D. Orden. 2008. "Avocado Pests and Avocado Trade." American Journal of Agricultural Economics 90(2):321-335.

Polinsky, A.M., and W. Rogerson. 1983. "Products Liability and Consumer Misperceptions and Market Power." The Bell Journal of Economics 14(2):581-589. 
Rauch, J.E. 1999. "Networks Versus Markets in International Trade." Journal of International Economics 48(1):7-35.

Redding, S., and A.J. Venables. 2004. "Economic Geography and International Inequality." Journal of International Economics 62(1):53-82.

Romalis, J. 2007. "NAFTA's and CUSFTA's Impact on International Trade." Review of Economics and Statistics 89(3):416-435.

Southern Shrimp Alliance. 2007. Request for Comments to the Presidential Interagency Working Group on Import Safety [Docket No.2007N-0330]. Tarpon Springs.

United Nations, Conference on Trade and Development. 2005. Methodologies, Classifications, Quantification and Development Impacts of Non-Tariff Barriers. TD/B/COM.1/EM.27/2. Geneva.

United Nations, Food and Agriculture Organization. 2009. FishStat Plus - Universal Software for Fishery Statistical Time Series. Rome.

Warr, P.G. 2001. "Welfare Effects of an Export Tax: Thailand's Rice Premium." American Journal of Agricultural Economics 83(4):903-920.

White, H. 1980. "A Heteroskedasticity-Consistent Covariance Matrix Estimator and a Direct Test for Heteroskedasticity." Econometrica 48(4):817-838.

Wilson, J.S., and T. Otsuki. 2004. "To Spray or not to Spray: Pesticides, Banana Exports, and Food Safety." Food Policy 29(2):131-146.

Wilson, N.L., and J. Anton. 2006. "Combining Risk Assessment and Economics in Managing a Sanitary-Phytosanitary Risk." American Journal of Agricultural Economics 88(1):194202.

World Bank. 2004. Saving Fish and Fishers. Toward Sustainable and Equitable Governance of the Global Fishing Sector. Report No. 29090-GLB. Washington DC.

World Trade Organization. 2008. Specific Trade Concerns. G/SPS/GEN/204/Rev.8. Geneva.

Yue, C., and J. Beghin. 2009. "Tariff Equivalent and Forgone Trade Effects of Prohibitive Technical Barriers to Trade." American Journal of Agricultural Economics 91(4):930941.

Yue, C., J. Beghin, and H.H. Jensen. 2006. "Tariff Equivalent of Technical Barriers to Trade with Imperfect Substitution and Trade Costs." American Journal of Agricultural Economics 88(4):947-960. 
Table 1. Impact of Standards on Chloramphenicol on Imports of Crustaceans, 2001-

2006

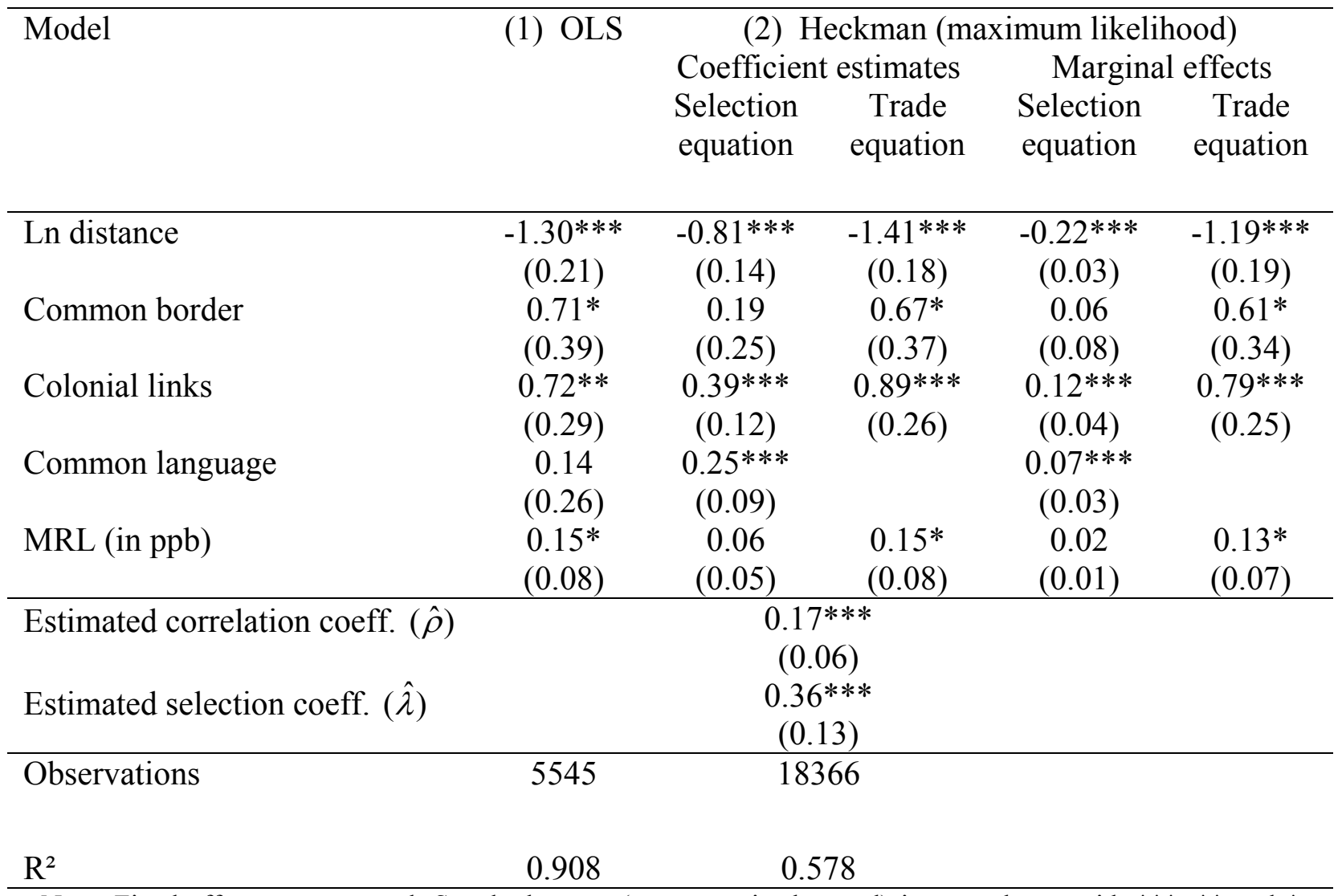

Note: Fixed effects not reported. Standard errors (country-pair clustered) in parentheses with $* * *, * *$ and $*$ denoting significance at the $1 \%, 5 \%$ and $10 \%$ levels. Common language is the excluded variable. 
Table 2. Values of Parameters for the Calibrated Model of Crustaceans, in 2001 and

2006

\begin{tabular}{lcccc}
\hline Variable & United States & Canada & Japan & European Union (EU15) \\
\hline Consumption in 2001 (tons) & 822,822 & 228,903 & 598,619 & 599,642 \\
Price $^{\mathrm{a}}$ in 2001 (US \$) & 10.02 & 5.43 & 8.89 & 6.12 \\
Consumption in 2006 (tons) $^{\text {a }}$ & $1,106,359$ & 196,676 & 513,342 & 717,772 \\
Price $^{\mathrm{a}}$ in 2006 (US \$) & 8.34 & 7.57 & 8.22 & 6.90 \\
Own-price elasticity of demand $^{\mathrm{b}}$ & -1.01 & -0.94 & -1.11 & -0.67 \\
Own-price elasticity of supply $^{\mathrm{c}}$ & 0.77 & 0.77 & 0.77 & 0.77 \\
MRL $^{\mathrm{d}}$ in 2001 (in ppb) & 5 & 2.5 & 50 & 1.5 \\
MRL $^{\mathrm{d}}$ in 2006 (in ppb) & 0.3 & 0.3 & 50 & 0.3
\end{tabular}

Note: Quantities and prices in 2001 and 2006 come from UN FAO (2009). ${ }^{\text {a: }}$ The domestic prices were estimated by dividing the value of imports by the quantity of imports (UN FAO 2009), since the import prices reflect and approximate the domestic prices. ${ }^{\mathrm{b}}$ : Asche and Bjørndal (2001) for crustaceans in Canada, Japan and the European Union and Hudson et al. (2003) for shrimps in the US by taking the average of own-price elasticities of demand over the 4 destinations in table 4 (p. 236). ${ }^{\text {c }}$ : Dey et al. (2004) for the aquaculture of shrimps by taking the average of own-price elasticities of demand over the top 5 world producers of shrimps in table 3 (p. 5). ${ }^{\text {d: }}$ MRLs for chloramphenicol come from Debaere (2005), the World Bank (2004), the European Commission Decision 2002/657/EC, and http://www.seafoodnews.com/ (available May 2009). 
Table 3. Welfare Changes for the Year 2001 Linked to Reduction of the MRL Between 2001 and 2006 (Ex Post Estimation)

\begin{tabular}{|c|c|c|c|c|}
\hline Country & \multicolumn{2}{|c|}{ Case $1(\bar{\gamma}=3 / 4)$} & \multicolumn{2}{|c|}{ Case $2(\bar{\gamma}=1 / 2)$} \\
\hline \multicolumn{5}{|l|}{ United States (\$) $\Delta \mathrm{MRL}=-4.7$} \\
\hline Domestic consumers and cost of ignorance & $1,047,487,072$ & $(596 \%)$ & $1,047,487,072$ & $(596 \%)$ \\
\hline Domestic producers & $1,731,883,229$ & $(105 \%)$ & $1,731,883,229$ & $(105 \%)$ \\
\hline Foreign exporters & - 3,391,342,546 & $(-100 \%)$ & - 3,391,342,546 & $(-100 \%)$ \\
\hline International welfare & $-611,972,244$ & $(-12.5 \%)$ & $-611,972,244$ & $(-12.5 \%)$ \\
\hline \multicolumn{5}{|l|}{ Canada (\$) $\triangle M R L=-2.2$} \\
\hline Domestic consumers and cost of ignorance & $80,552,216$ & $(33 \%)$ & $141,320,491$ & $(58 \%)$ \\
\hline Domestic producers & $98,498,885$ & $(23 \%)$ & $98,498,885$ & $(23 \%)$ \\
\hline Foreign exporters & $-106,550,071$ & $(-31 \%)$ & $-106,550,071$ & $(-31 \%)$ \\
\hline International welfare & $72,501,030$ & $(7.2 \%)$ & $133,269,305$ & $(13.1 \%)$ \\
\hline \multicolumn{5}{|l|}{ Japan (\$) $\Delta M R L=0$} \\
\hline Domestic consumers and cost of ignorance & 0 & $(0 \%)$ & 0 & $(0 \%)$ \\
\hline Domestic producers & 0 & $(0 \%)$ & 0 & $(0 \%)$ \\
\hline Foreign exporters & 0 & $(0 \%)$ & 0 & $(0 \%)$ \\
\hline International welfare & 0 & $(0 \%)$ & 0 & $(0 \%)$ \\
\hline \multicolumn{5}{|l|}{ European Union (\$) $\Delta \mathrm{MRL}=-1.2$} \\
\hline Domestic consumers and cost of ignorance & $496,337,759$ & $(75.5 \%)$ & $843,646,896$ & $(128.4 \%)$ \\
\hline Domestic producers & $113,878,501$ & $(14.5 \%)$ & $113,878,501$ & $(14.5 \%)$ \\
\hline Foreign exporters & $-238,933,024$ & $(-16 \%)$ & $-238,933,024$ & $(-16 \%)$ \\
\hline International welfare & $371,283,237$ & $(23.4 \%)$ & $718,592,373$ & $(45.3 \%)$ \\
\hline
\end{tabular}

Note: Relative variation (\%) compared to the baseline scenario in parentheses. 
Table 4. Welfare Changes for the Year 2006 with a Potential MRL Equal to Zero (Ex Ante Estimation)

\begin{tabular}{lcccc}
\hline Country & Case $3(\bar{\gamma}=1 / 2)$ & \multicolumn{2}{c}{ Case $4(\bar{\gamma}=1 / 4)$} \\
\hline United States (\$) $\mathbf{M M R L}=\mathbf{- 0 . 3}$ & & & & \\
Domestic consumers and cost of ignorance & $1,009,307,475$ & $(120 \%)$ & $2,140,755,629$ & $(255 \%)$ \\
Domestic producers & $142,331,159$ & $(8 \%)$ & $142,331,159$ & $(8 \%)$ \\
Foreign exporters & $-159,071,683$ & $(-4 \%)$ & $-159,071,683$ & $(-4 \%)$ \\
International welfare & $992,566,952$ & $(15.3 \%)$ & $2,124,015,106$ & $(32.7 \%)$ \\
Canada (\$) $\Delta \mathbf{M R L}=\mathbf{- 0 . 3}$ & & & & $(51.3 \%)$ \\
Domestic consumers and cost of ignorance & $108,496,719$ & $(25.1 \%)$ & $221,822,688$ & $(2.7 \%)$ \\
Domestic producers & $14,676,010$ & $(2.7 \%)$ & $14,676,010$ & $(-3.6 \%)$ \\
Foreign exporters & $-14,079,402$ & $(-3.6 \%)$ & $-14,079,402$ & $(-3 \%)$ \\
International welfare & $109,093,328$ & $(8.1 \%)$ & $222,419,296$ & $(16.5 \%)$
\end{tabular}

Japan (\$) $\Delta \mathrm{MRL}=\mathbf{- 5 0}$

Domestic consumers and cost of ignorance

$-272,056,055$

$(-57.1 \%) \quad-272,056,055 \quad(-57.1 \%)$

Domestic producers

$815,211,563 \quad(182 \%) \quad 815,211,563 \quad(182 \%)$

Foreign exporters

$\begin{array}{llll}-2,133,945,899 & (-100 \%) & -2,133,945,899 & (-100 \%)\end{array}$

International welfare

$-1,590,790,391 \quad(-52 \%) \quad-1,590,790,391 \quad(-52 \%)$

\section{European Union (\$) $\Delta \mathrm{MRL}=\mathbf{- 0 . 3}$}

Domestic consumers and cost of ignorance $\quad 536,655,351 \quad(108 \%) \quad 1,133,306,985 \quad(230 \%)$

Domestic producers $\quad 74,744,486 \quad(7.9 \%) \quad 74,744,486 \quad(7.9 \%)$

Foreign exporters $\quad-86,670,164 \quad(-3.9 \%) \quad-86,670,164 \quad(-3.9 \%)$

International welfare $\quad 528,729,673 \quad(15 \%) \quad 1,125,381,307 \quad(31.9 \%)$ 


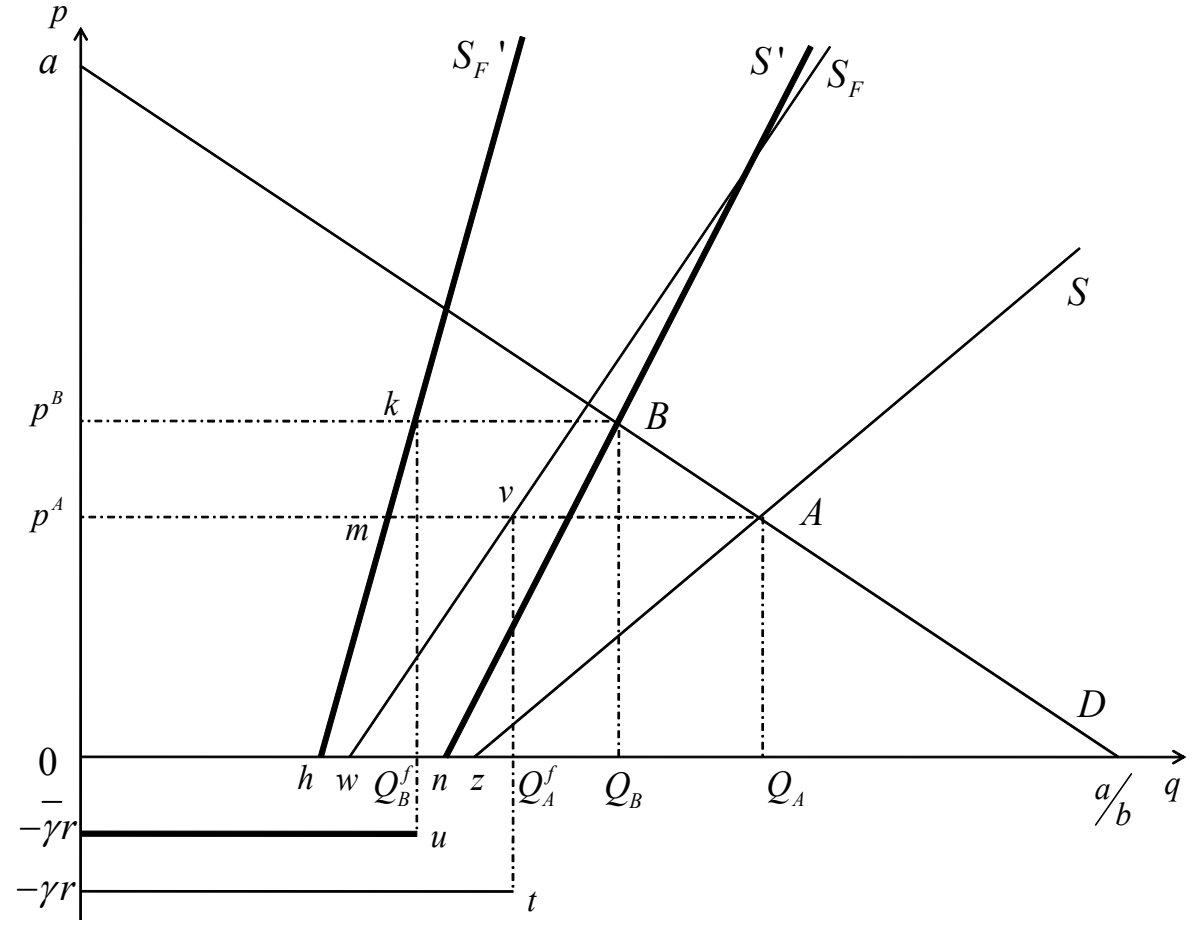

Figure 1. Market Equilibrium 